\title{
Treatment of mitral regurgitation
}

\author{
Roberto Violini, Alberta Cifarelli, Francesco De Felice, Diana Chin \\ UO Cardiologia Interventistica, Azienda Ospedaliera S. Camillo Forlanini, Rome, Italy
}

\begin{abstract}
In the elderly mitral regurgitation is very frequent and surgical correction of mitral regurgitation (MR) has often a high operative risk, consequently, over the years, different percutaneous transcatheter techniques have been developed as a valid alternative to surgery. The edge-to-edge repair with the MitraClip device has gained a wide clinical application, supported by several studies, both randomized trials and registries. It is indicated in functional MR as in degenerative MR. The outcome is usually positive, resulting in a reduction of the regurgitation to grade $1+$ or $2+$ and an improvement in the NYHA functional class to I or II, even reducing the hospitalizations. Its cost-effectiveness too is supported by some studies.
\end{abstract}

\section{Introduction}

Mitral regurgitation (MR) is a relatively frequent cardiac disease in the elderly and often results in significant morbidity and mortality. Its pathogenesis can be primary (degenerative), due to leaflet malformations (prolapse), chordal rupture or tissue degeneration of the mitral valve (MV), or secondary (functional) when there is no valvular disease but the regurgitation is due to ventricular remodeling (regional or global) with modifications of the papillary muscles, dilatation of the annulus and reduction of leaflet coaptation. The etiology is usually ischemic or dilatative cardiomyopathy [1]. In the former, surgical correction is effective, usually done with MV repair, rather than replacement, and has been associated with first-time operative mortality rates near $2 \%$, and re-operative mortality rates near $8 \%$ [2]. The surgical intervention in the functional forms has a worse outcome and is often not indicated.

Corresponding author: Roberto Violini, UO Cardiologia Interventistica, Azienda Ospedaliera S. Camillo Forlanini, Piazza Carlo Forlanini 1, 00151 Roma, Italy. E-mail: r.violini@scf.gov.it

Key words: Elderly; MitraClip®; mitral regurgitation; percutaneous; transcatheter.

Received for publication: 26 April 2017

Accepted for publication: 4 May 2017

CCopyright R. Violini et al., 2017

Tipografia PI-ME Editrice, Italy

Monaldi Archives for Chest Disease 2017; 87:854

doi: 10.4081/monaldi.2017.854

This article is distributed under the terms of the Creative Commons Attribution Noncommercial License (by-nc 4.0) which permits any noncommercial use, distribution, and reproduction in any medium, provided the original author(s) and source are credited.
Obviously, the surgical risk is significantly higher in older patients, so different percutaneous techniques are being clinically evaluated in order to treat surgical high risk patients. The transcatheter approaches are different: some of them aim to reduce annulus enlargement, whilst the MitraClip ${ }^{\circledR}$ system reproduces the Alfieri surgical operation, with the edge-to-edge repair to reduce valvular regurgitation. Actually, only this technique has emerged as a widespread transcatheter method for treating MR (implanted in over 40.000 patients worldwide) whilst the direct and indirect anuloplasty methods are also moving their first steps in the clinical world.

\section{Technique}

The MitraClip ${ }^{\circledR}$ device is inserted via the femoral vein and utilizes a 24Fr guiding catheter to gain transseptal access to the left atrium. The tip of this catheter has a bidirectional steering mechanism so it can be positioned centrally above the mitral valve annulus and a Vshaped clip is introduced while closed. This clip, made of cobaltchromium and polyester-covered, is opened and advanced into the left ventricle; then it is slowly retracted to snare the anterior and posterior leaflets during systole; the clip can be opened and closed repeatedly to ensure optimal positioning. When the grasping appears optimal, the clip is released, so creating a double valvular orifice (Figure 1). Sometimes more than one clip, up to three or four, are used to gain the best result.

After the implant a regimen of aspirin at a dose of $325 \mathrm{mg}$ daily for 6 months with clopidogrel at a dose of $75 \mathrm{mg}$ daily for 1 month is suggested [2], although this therapy has not been validated.

\section{Studies}

In the first randomized trial comparing the MitraClip ${ }^{\circledR}$ device versus standard MV surgery [3], two hundred and seventy-nine patients with grade 3+ MR were randomized in a 2:1 ratio to undergo MitraClip ${ }^{\circledR}$ implantation or conventional surgical MV correction (either repair or replacement). The composite endpoint of freedom from death, surgery, or grade 2+ MR at 12 months was achieved in $55 \%$ of MitraClip ${ }^{\circledR}$ patients vs $73 \%$ of surgical patients $(\mathrm{p}=0.007)$; Both groups demonstrated similar symptom reduction up to 24 months, while surgical patients experienced superior decreases in MR grade, (76\% demonstrating MR grade $1+v s 43 \%$ of MitraClip ${ }^{\circledR}$ patients). The authors concluded that, though surgery appeared more effective in treating MR, percutaneous treatment was also effective and safer in a large number of patients and was associated with lower rates of major adverse events (15\% of MitraClip® patients vs $48 \%$ of surgical patients).

Several studies of "real-world" experience with the MitraClip® system have been published with satisfactory results. A large European study, the Amsterdam Center for Contemporary European Studies - A Two-Phase Observational Study of the MitraClip ${ }^{\circledR}$ System in Europe (ACCESS-EU) prospective nonrandomized trial, found $81.8 \%$ survival at 1 year and $78.9 \%$ 


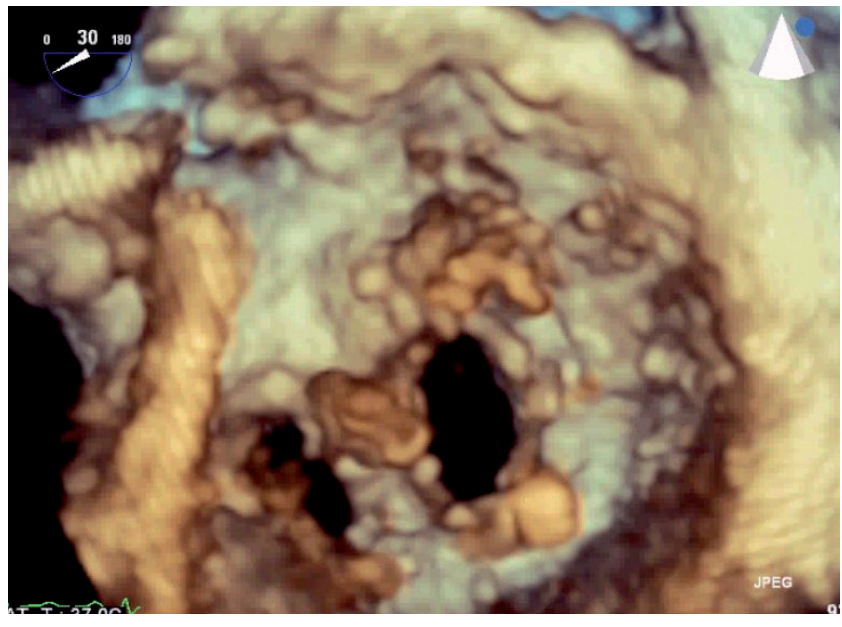

Figure 1. Transesophageal three-dimensional echocardiogram showing the double orifice after MitraClip implantation.

freedom from MR grade 3+ [4]. The Getting Reduction of Mitral Insufficiency by Percutaneous Clip Implantation (GRASP) registry showed freedom from the composite endpoint of death, surgery, or MR grade $3+$ in $75.8 \%$ of 117 treated patients at 1 year [5].These data also did not show any differences in safety or outcomes when comparing patients with degenerative $v s$ functional MR. A recent meta-analysis reviewing 16 studies confirmed a low adverse event rate and only $14.7 \%$ of patients demonstrating MR grade $3+$ at 1 year [6]. The largest series of treated patients (749 patients with 1-year follow-up from the German transcatheter mitral valve interventions registry) demonstrated $79.7 \%$ 1-year survival among all patients, as well as a decreased rate of hospital readmission for heart failure [7].

The MitraClip ${ }^{\circledR}$ has been beneficial in several other experiences: survival of $98.3 \%$ in the percutaneous therapy group compared to $89.7 \%$ in the conservative group at 1 year and $61.4 \%$ vs $34.9 \%(\mathrm{p}=0.007)$ at 3 years were demonstrated in a recent study of 60 patients treated with MitraClip compared to 60 patients managed medically [8].

Other studies were conducted in patients with renal impairment [9], in patients with grade $3+$ MR nonresponsive to cardiac resynchronization therapy [10] and in end-stage systolic heart failure patients [11].

\section{Indications}

At present, the MitraClip ${ }^{\circledR}$ implant is indicated in patients with severe MR despite optimal medical therapy, who are not surgical candidates, for high risk (degenerative MR) or lack of indication (functional MR in cardiomyopathies), when life expectancy is longer than one year and when a Heart Team confirms the indication. In the ESC guidelines MitraClip ${ }^{\circledR}$ has a recommendation in class IIb, evidence level C [12]. The predictors of 1-year mortality [6] are summarized in Table 1. Anatomical criteria are evolving and are actually larger than in the Everest trial. In the elderly, the frequent fibroelastic degeneration of MV seems an indication with a favorable outcome.

\section{Final considerations}

The indications of MitraClip ${ }^{\circledR}$ therapy in patients with functional MR have gained an important role, because these patients have worse
Table 1. Predictors of 1-year mortality after MitraClip ${ }^{\circledR}$ intervention [6] (modified).

\author{
NYHA IV \\ Anemia \\ Previous aortic valve intervention \\ Creatinine $\geq 1-5 \mathrm{mg} / \mathrm{dl}$ \\ Peripheral artery disease \\ Left ventricular ejection fraction $<30 \%$ \\ Severe tricuspid regurgitation \\ Procedural failure
}

outcomes following valve repair compared to degenerative MR [13]. Recently mitral valve replacement too has been demonstrated to have equivalent outcomes for functional MR patients in a randomized trial, even though earlier data has suggested a superior outcomes for MV repair [14]. However, an excess incidence of recurrent MR was noted at 1-year among patients undergoing MV repair [15].

In the US, the MitraClip system is currently approved by the Food and Drug Administration for patients with degenerative MR grade 3+ and symptoms (New York Heart Association functional class III or IV) who meet prohibitive risk criteria (30-day Society of Thoracic Surgeons predicted operative mortality risks of $8 \%$ for planned mitral valve replacement, or $6 \%$ for planned MVR).

The MitraClip® device does not solve all aspects of mitral valve dysfunction which result in MR: it improves leaflet coaptation, but does not modify the mitral annulus (as it can be done surgically by suturing a ring) nor does it correct problems related to the mitral chordal apparatus. Consequently, different technologies designed to improve annular geometry or chordal function are under development, where a number are already being introduced for clinical use.

At present, in order to evaluate MitraClip ${ }^{\circledR}$ cost effectiveness in patients with MR and severe heart failure, a comparison must be done $v s$ medical treatment, and not $v s$ surgical intervention as most patients receiving the clip are not suitable for surgery. This comparison should be done calculating how many hospitalizations are saved after the MitraClip® implantation. Several papers demonstrate that MitraClip ${ }^{\circledR}$ is cost effective $[1,16]$. Finally, some randomized controlled trials (Reshape, Mitral FR, COAPT) are currently enrolling patients to compare efficacy of MitraClip ${ }^{\circledR} v$ s best medical therapy in the treatment of heart failure and severe MR.

The future of severe MR treatment is projected towards percutaneous mitral valve implantation: the first in man experiences have already been done with at least five different prosthesis.

\section{References}

1. Bedogni F, Berti S, Esposito G, et al. [Trattamento transcatetere dell'insufficienza mitralica per i pazienti non eleggibili all'intervento chirurgico: epidemiologia, diagnosi, equità di accesso ed impatto economico].[Article in Italian]. G Ital Cardiol 2017;18(2 Suppl 1):3S-8S.

2. Block, PC. Percutaneous mitral valve repair for mitral regurgitation. J Interv Cardiol 2003;16:93-6.

3. Feldman T, Foster E, Glower DD, et al. Percutaneous repair or surgery for mitral regurgitation. N Engl J Med 2011;364:1395-406.

4. Maisano F, Franzen 0, Baldus S, et al. Percutaneous mitral valve interventions in the real world: early and 1-year results from the ACCESS-EU, a prospective, multicenter, nonrandomized post- 
approval study of the MitraClip therapy in Europe. J Am Coll Cardiol 2013;62:1052-61.

5. Grasso C, Capodanno D, Scandura S, et al. One- and twelve-month safety and efficacy outcomes of patients undergoing edge-to-edge percutaneous mitral valve repair (from the GRASP Registry). Am J Cardiol 2013;111:1482-7.

6. Vakil K, Roukoz H, Sarraf M, et al. Safety and efficacy of the MitraClip ${ }^{\circledR}$ system for severe mitral regurgitation: a systematic review. Catheter Cardiovasc Interv 2014;84:129-36.

7. Puls M, Lubos E, Boekstegers P, et al. One-year outcomes and predictors of mortality after MitraClip therapy in contemporary clinical practice: results from the German transcatheter mitral valve interventions registry. Eur Heart J 2016;37:703-12.

8. Giannini C, Fiorelli F, De Carlo M, et al. Comparison of percutaneous mitral valve repair versus conservative treatment in severe functional mitral regurgitation. Am J Cardiol 2015;117:271-7.

9. Schueler R, Nickenig G, May AE, et al. Predictors for short-term outcomes of patients undergoing transcatheter mitral valve interventions: analysis of 778 prospective patients from the German TRAMI registry focusing on baseline renal function. EuroIntervention. Epub 2015 Sep 8;11(5).
10. Seifert M, Schau T, Schoepp M, et al. MitraClip in CRT non-responders with severe mitral regurgitation. Int J Cardiol 2014; 177:79-85.

11. Franzen 0, van der Heyden J, Baldus S, et al. MitraClip ${ }^{\circledR}$ therapy in patients with end-stage systolic heart failure. Eur J Heart Fail 2011; 13:569-76.

12. Vahanian A, Alfieri 0, Andreotti F, et al. Guidelines on the management of valvular heart disease (version 2012). Eur Heart J 2012; 33:2451-96.

13. Jensen H, Jensen MO, Nielsen SL. Surgical treatment of functional ischemic mitral regurgitation. J Heart Valve Dis 2015;24:30-42.

14. Acker MA, Parides MK, Perrault LP, et al. Mitral-valve repair versus replacement for severe ischemic mitral regurgitation. $N$ Engl J Med 2014;370:23-32.

15. Magruder JT, Crawford TC, Grimm JC, et al. Managing mitral regurgitation: focus on the MitraClip device. Med Devices (Auckl) 2016;9:53-60.

16. Armeni P, Boscolo PR, Tarricone R, et al. Real-world cost effectiveness of MitraClip combined with medical therapy versus medical therapy alone in patients with moderate or severe mitral regurgitation. Intern J Cardiol 2016;209:153-60. 